\title{
COVID-19 pandemic and tourism: The impact of health risk perception and intolerance of uncertainty on travel intentions
}

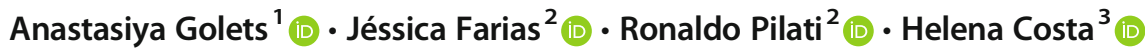 \\ Accepted: 31 August 2021 / Published online: 13 September 2021 \\ (C) The Author(s), under exclusive licence to Springer Science+Business Media, LLC, part of Springer Nature 2021
}

\begin{abstract}
Understanding tourist behavior during and after major tourism crises is essential to help destinations recover. The COVID19 pandemic - a period of uncertainty and risk - makes it relevant to assess factors that influence travel intentions. There has been little research on tourist behavior during health crises and, in particular, on perceived health risk and uncertainty effects on travel intentions. This study was carried out at the beginning of the pandemic in Brazil and aims to investigate the role of health risk perception and intolerance of uncertainty on travel intentions for 2020 and 2021. We applied an online survey to 1150 Brazilian participants from April to May 2020. Our findings indicate that perceived COVID-19 severity, perceived probability of infection, and expected duration of the pandemic are significant predictors of travel intentions for both years. This paper contributes to a deeper understanding of crisis-resistant tourists' characteristics and provides insights for destinations' recovery.
\end{abstract}

Keywords COVID-19 $\cdot$ pandemic $\cdot$ travel intentions $\cdot$ health risk perception $\cdot$ intolerance of uncertainty

Since the beginning of the twenty-first century, the world has been facing several emerging and re-emerging virus outbreaks such as H5N1 (avian flu), SARS, H1N1 (swine flu), MERS, Ebola, Zika, among others (Bedford et al., 2019). On 31 December 2019, a highly contagious coronavirus disease (COVID-19) was detected in Wuhan city, China. In the first three months, the virus infected more than 750,000 people in 172 countries and caused more than 36,000 deaths, which led the World Health Organization to declare a pandemic (World Health Organization, 2020). In an attempt to contain the rapid spread of the COVID-19 outbreak and prevent the collapse of health systems, national governments adopted measures such as closure of schools, travel restrictions, and quarantines (Nicola et al., 2020).

Anastasiya Golets

anastasiya.golets@gmail.com

1 Centre of Sustainable Development, University of Brasilia, Brasilia, Brazil

2 Institute of Psychology, University of Brasilia, Brasilia, Brazil

3 Faculty of Business Administration, Accounting, Economics and Public Policy Management, University of Brasilia, Brasilia, Brazil
The travel industry was one of the most affected by the pandemic. The COVID-19 outbreak has caused the worst crisis faced by international tourism since the 1950s when UNWTO started to analyze international tourism trends (World Tourism Organization, 1980). In the first half of 2020 , international tourist arrivals dropped by $65 \%$, if compared to the same period in 2019. At the time this study was conducted, $100 \%$ of destinations worldwide had restricted travel to a certain extent, and $76 \%$ of destinations had closed their borders completely or partially (World Tourism Organization, 2020b, 2020c). This impact has already been translated into a loss of about U $\$ 460$ billion in export revenues from international tourism, which accounts for around five times the financial loss of the 2009 global economic crisis. Moreover, it has put between 100 and 120 million direct tourism jobs at risk. According to UNWTO scenarios, the return to 2019 tourist arrivals levels would take from two to 4 years (World Tourism Organization, 2020a, 2020c).

As in most destinations, the Brazilian tourism sector has been strongly impacted by the COVID-19 outbreak (Tomé, 2020). In the first half of 2020 , the country's revenues from inbound tourism fell by $37.20 \%$, while outbound spending of Brazilian tourists presented a decrease of $59.40 \%$ when compared to the same period in 2019. The sector lost 364,044 formal jobs by July, which corresponds to about $12 \%$ of all 
formal tourism jobs in 2019 (CNC, 2019; Ministério do Turismo, 2020). The total loss of the Brazilian tourism industry is estimated to be around U\$22 billion in the 2020-2021 biennium. To reach the pre-pandemic level, the industry will have to grow by $17 \%$ per year in 2022 and 2023 (FGV, 2020). Therefore, understanding individuals' travel intentions in the context of a pandemic - a period that involves a great level of uncertainty and risk management - is a crucial component in developing destination recovery strategies.

There has been little discussion on the effect of uncertainty on tourism. Previous studies have found that tourists from high uncertainty avoidance (UA) national cultures differ from the medium UA ones when it comes to trip planning, travel style (Money \& Crotts, 2003), decisionmaking, trip duration, and the main source of information used (Litvin et al., 2004). Moreover, trips to similar or different uncertainty avoidance national cultures have distinct characteristics (Crotts, 2004). Notwithstanding, to the best of our knowledge, there has not been any research on the influence of intolerance of uncertainty (IU) - an individual difference variable (Carleton et al., 2007) — on travel intentions. Considering that Brazil is a country whose members feel uncomfortable with uncertainty and ambiguity (Hofstede Insights, n.d.), a pandemic could be particularly stressful to its population. Seeing that uncertainty can minimize the effectiveness of preparing for the future and contribute to anxiety (Grupe \& Nitschke, 2013; Tanovic et al., 2018), the COVID-19 pandemic is expected to cause such detrimental effect on people in general, and, considering the high score on the cultural value of uncertainty avoidance, this effect is expected to hold even stronger in Brazil.

This study was carried out in Brazil during the first bimester of the COVID-19 pandemic and aims at analyzing the influence of the individual difference variable of IU as well as the perceived severity of the disease, the perceived probability of infection, and the expected duration of the pandemic on travel intentions for the years 2020 and 2021. We also control for the effect of some sociodemographic measures (international travel experience, age, educational level, and income) on these intentions. The contribution of our study lies in shedding light on psychological processes that underlie traveler behavior during crises and providing a deeper understanding of crisis-resistant tourists' characteristics, which is essential for destinations' post-crisis recovery.

\section{Theoretical Framework}

\section{Uncertainty and Tourist Behavior}

Uncertainty avoidance (UA) consists of a cultural value that expresses the degree to which the members of a society feel uncomfortable with uncertain situations (Hofstede et al., 2010). Cultures high on uncertainty avoidance prize structure and feel threatened by the unknown and the ambiguous whereas cultures low on uncertainty avoidance are more willing to accept risks (Litvin et al., 2004). Some tourism and travel research has been conducted to investigate the influence of this cultural dimension on tourist behavior. For instance, it has been found that high uncertainty-avoidant Japanese prefer to pre-package risk-reducing elements of the trip and to travel in big groups of people (Money \& Crotts, 2003). Contrastingly, low uncertainty-avoidant Germans and Australians are prone to engage in risky activities and seek excitement while traveling (Money \& Crotts, 2003; Reisinger \& Mavondo, 2005). Brazil is characterized as high uncertainty-avoidant culture (Hofstede Insights, n.d.). Therefore, it is expected that, when facing ambiguity or uncertainty, Brazilians tend to evade making choices to avoid discomfort.

Apart from the cultural value of UA, which reflects how members of a certain society cope with uncertainty at a collective level, individuals may differ in the degree to which they can stand aversive responses triggered by the perception of uncertainty and lack of information (Carleton et al., 2016). That is, they may differ in levels of intolerance of uncertainty (IU), which is an individual difference characteristic. IU is the tendency to consider the possibility of a negative event occurring as unacceptable regardless of its probability of occurrence is named intolerance of uncertainty (Carleton et al., 2007). Uncertainty, in its turn, can have detrimental effects on individuals since it can minimize the effectiveness of preparing for the future and contribute to anxiety (Grupe \& Nitschke, 2013; Tanovic et al., 2018). Notwithstanding, there are not many studies in the tourism literature which assess the role of uncertainty in travel decisions (Minnaert, 2014). Some exceptions are the reports that more extensive travel experience results in a decrease in the role of uncertainty factors (Quintal et al., 2010) and that potential travelers with lower uncertainty levels are more likely to take part in 'challenging' tourism activities (Minnaert, 2014). Considering the relationship between IU and avoidance of aversive responses, we suggest that:

H1. Individuals who hold high IU are likely to have weaker intentions of traveling in 2020 and 2021.

\section{Tourism and Risk Perception}

There are several concepts of risk perception in tourism studies (Tsaur et al., 1997; Sönmez \& Graefe, 1998a; Reichel et al., 2007; Liu \& Gao, 2008; Chen \& Zhang, 2012). Despite little discordance in the academic literature, tourism 
risk perception is usually considered to be a potential loss that stems from the uncertainty of the tourism activity results (Roehl \& Fesenmaier, 1992; Sönmez \& Graefe, 1998b). It is related to several consequences in consumer behavior, including purchase intention (Liu et al., 2013; Mohseni et al., 2016), (re)visit intention (Chew \& Jahari, 2014; Rittichainuwat \& Chakraborty, 2009; Zhu \& Deng, 2020), and satisfaction (Quintal \& Polczynski, 2010; Xie et al., 2020), and loyalty (Casidy \& Wymer, 2016; Chahal \& Devi, 2017). Previous studies have revealed that perceived tourism risk may decrease re(visit) intention in case of natural disasters (Chew \& Jahari, 2014; Lehto et al., 2008; Rittichainuwat et al., 2018), terrorism (Sönmez \& Graefe, 1998b; Floyd et al., 2004; Adeloye \& Brown, 2017), and diseases (Mizrachi \& Fuchs, 2016; Nazneen et al., 2020; Neuburger \& Egger, 2020; Novelli et al., 2018). Notably, the impact of health concerns on tourism has aroused growing academic interest in the past two decades (Hamer \& Connor Bradley, 2004; Jonas et al., 2010; Lopez-Velez \& Bayas, 2007; Novelli et al., 2018; Senbeto \& Hon, 2020). Among all the perceived tourism-related risks, health ones are reported to be some of the factors that hold the most considerable influence on tourist behavior (Chien et al., 2017; Kozak et al., 2007; McKercher \& Chon, 2004; Novelli et al., 2018; Sönmez \& Graefe, 1998b). Major health crises, such as 2003 SARS and 2015 avian flu outbreaks, seem to impact tourist behavior more than a financial crisis, causing anxiety and impacting travel intentions regardless of the tourists' profile (Senbeto \& Hon, 2020). In a similar vein, studies addressing the COVID-19 pandemic (Nazneen et al., 2020; Neuburger \& Egger, 2020) have shown that tourist health risk perception has increased during the pandemic, affecting individuals' travel intentions negatively.

To assess tourist health risk perception, several authors have proposed to consider perceived severity, that is, severe negative health impacts of the disease (Brewer et al., 2007; Provost \& Soto, 2002). Perceived severity is an indicator of the health belief model (HBM), used to predict health-related behavior in various contexts (Janz \& Becker, 1984; Jones et al., 2014). Individuals who perceive a disease to be highly severe and to have potential complications are reported to take measures to avoid getting sick (Champion \& Skinner, 2008). In the travel and tourism context, greater perceived severity can also lead to health-preventative behaviors and lower travel intentions (Brewer et al., 2007; Champion \& Skinner, 2008; Das \& Tiwari, 2020; Huang et al., 2020). Thus, we hypothesize that:

H2. Individuals who perceive COVID-19 to be more severe will have weaker intentions of traveling in 2020 and 2021.
Moreover, perceived susceptibility - the likelihood of acquiring a disease - is another HBM indicator used by tourism researchers (Brewer et al., 2007; Das \& Tiwari, 2020; Floyd et al., 2000; Huang et al., 2020; Janz \& Becker, 1984; Jones et al., 2014; Neuburger \& Egger, 2020). Individuals with a higher perceived susceptibility are reported to have a negative attitude towards risks and take preventive behaviors (Taymoori et al., 2014). This is also valid for travel and tourism studies, which show that these travelers are more prone to engage in risk mitigation measures and to avoid risks (Van der Plight, 1996; Chien et al., 2017; Zhang et al., 2018; Huang et al., 2020). Consequently, we propose that:

H3. Individuals who perceive the probability of contracting COVID-19 as high will have weaker intentions of traveling in 2020 and 2021.

In addition to that, some studies have shown that the expected outbreak duration can predict behavior changes. In the context of the swine flu outbreak, the expected timeline of the epidemic was associated with several avoidance behaviors (Rubin et al., 2009). As to tourism, Li et al. (2020) suggested that expected outbreak duration could predict tourist behavior. The longer the outbreak is expected to last, the least strong travel intentions tend to be. Therefore, we hypothesize that:

H4. Individuals who expect the COVID-19 pandemic to last longer will have weaker intentions of traveling in 2020 and 2021.

\section{Other Determinants of Travel Intentions}

Several studies on tourist behavior have found that some individual characteristics may affect travel intentions. Variables such as age (Hajibaba et al., 2015; Khan et al., 2018; Neuburger \& Egger, 2020), travel experience (Kozak et al., 2007; Polas et al., 2019; Sönmez \& Graefe, 1998a), income (Sönmez \& Graefe, 1998b; Floyd et al., 2004; Djeri et al., 2014; Li et al., 2018), and education level (Qi et al., 2009; Sönmez \& Graefe, 1998b) were relevant predictors of travel intentions also during periods of crises.

Travel Experience Previous studies have shown that more internationally experienced tourists tend to have stronger intentions of traveling during periods of crisis (Floyd et al., 2004; Pennington-Gray et al., 2011; Rittichainuwat \& Chakraborty, 2009; Sönmez \& Graefe, 1998b). Travel experience decreases tourist risk perception and, at the same time, positively influences travel intentions (Kozak 
et al., 2007; Neuburger \& Egger, 2020; Polas et al., 2019; Rittichainuwat \& Chakraborty, 2009; Sönmez \& Graefe, 1998a). In a similar vein, past travel experience seems to provide a greater sense of safety to tourists (Reza \& Samiei, 2012) and alters travel decisions more than information from external sources (Rittichainuwat \& Chakraborty, 2009). In line with Sönmez and Graefe (1998a) as well as Rittichainuwat and Chakraborty (2009), we expect that individuals with more international travel experience will tend to hold stronger travel intentions for 2020 and 2021.

Age Age has been found to be a predictor of tourist risk perception and travel intentions (Hajibaba et al., 2015; Khan et al., 2018). Prior research has shown that older individuals are likely to avoid visiting tourist destinations with greater perceived risks (Aschauer, 2010; March \& Woodside, 2005), while the younger ones are less concerned about physical tourism-related risks and show stronger travel intentions. Young tourists are also more short-time oriented and likely to visit a post-disaster destination (Chew \& Jahari, 2014). By considering this rationale, it makes sense that younger individuals tend to have stronger travel intentions for 2020 and 2021.

Income Higher-income levels were associated with stronger travel intentions. Studies have shown that there is a relationship between income and travel intentions both in risky and riskless times (Djeri et al., 2014; Floyd et al., 2004; Li et al., 2018; Sönmez \& Graefe, 1998b). In a riskless context, Djeri et al. (2014) found that individuals with a higher income spend their free time in a more active way than those with a lower income, which implies more frequent traveling among the former. In a risky context, Floyd et al. (2004) discovered that, among the socio-demographic variables, income was the single significant predictor of travel intentions in the aftermaths of a terrorist act. Therefore, it is conceivable that individuals holding higher income levels be more likely to travel in the face of the COVID-19 pandemic.

Education Level Tourist concern for safety declines as the education levels increase. This has been supported by Qi et al. (2009), who argue that travelers with higher education levels tend to be more adventurous and to travel despite possible risks. Graburn (1983) states that tourists with more years of education are mostly in search of new experiences and are more likely to explore. Besides, more educated tourists show more positive travel attitudes when there are possible risks involved (Sönmez \& Graefe, 1998b). Based on this information, we expect that individuals with a greater educational level tend to have stronger travel intentions in 2020 and 2021.

\section{Method}

\section{Participants}

Participants were obtained through convenience sampling. A total of 1163 participants answered an online questionnaire, of which 13 participants were removed from the sample. There were 810 women $(70.43 \%), 331$ men $(28.78 \%)$, and nine participants who did not report gender $(0.78 \%)$. The mean age was $39.22(\mathrm{SD}=12.42)$, ranging from 18 to 80 years. As for income, the most cited income bracket $(n=354)$ was from four to ten minimum wages. Our sample is highly educated, for 591 (51.39\%) participants checked the graduate option, meaning they either are postgraduate students or have already finished a postgraduate degree, and 387 (33.65\%) indicated to have finished an undergraduate degree. Our sample has considerable domestic travel experience, for 836 (72.68\%) participants took six or more trips over the past five years. They also have some international experience, for 395 (34,34\%) made six or more trips over the past five years. There were participants from all the 26 Brazilian states and the Federal District. Most of them were from the State of São Paulo and the Federal District $(28.08 \%$ and $21.04 \%$, respectively). Detailed sociodemographic characteristics are illustrated in Appendix Table 1.

\section{Measures}

\section{Travel Plans}

Two closed-ended questions about whether participants had actual travel plans for the years 2020 and 2021. Participants answered in a binary way, by either answering yes or no. We also asked two questions about whether COVID-19 had affected their travel plans for 2020 and 2021, which were also answered in a binary way. Additionally, we applied two closed-ended questions to the participants who answered yes in the previous question. These questions inquired about how their trips had been affected and comprised three options: Trip canceled, trip rescheduled, and other. In the realm of this study, we considered cancellation more of an avoidant option in that, when one opts for canceling, travel plans are extinguished. On the other hand, when one chooses to reschedule, there remains the intention of traveling in the future.

\section{Travel Intentions}

This measure consists of two scales that were developed in the scope of this research. They consist of four items in 
which participants stated how likely they were to travel in 2020 and 2021. To assess whether the answers would differ in the two years, two separate scales with the same items were applied. The scale was scored at five points $(1=$ No intention, 2 = Low intention, 3 = Average intention, $4=$ High intention, and $5=$ Very high intention). Items were as follows: "going ahead with your travel plans", "postponing your trip", "canceling your trip", and "keeping your trips unchanged". The higher the score was, the stronger the intentions of traveling were. By conducting exploratory factor analysis, we observed that the extraction of one factor explains $57.89 \%$ of the measure's total variance for 2020 and $62.71 \%$ for 2021. Eigenvalues and parallel analysis indicated the extraction of one factor. Bartlett's test of sphericity indicated that the overall significance of all the correlations within the correlation matrix for travel intentions in 2020, $\chi 2(1,150)=1173.95, \mathrm{p}<0.001$, and 2021, $\chi^{2}(1,150)=1602.15, p<0.001$. The strength of the relationships among variables was acceptable for 2020 $(\mathrm{KMO}=.70)$ and $2021(\mathrm{KMO}=.72)$. The Cronbach's $\alpha$ coefficient of the scales was .75 and .78 for travel intentions in 2020 and 2021, respectively.

\section{Past Travel Experience}

This measure was developed in the scope of this study to assess participants' previous travel experience. Participants answered three items about the frequency they had traveled to (1) cities of the state where they live, (2) other Brazilian states, and (3) other countries. The measure was scored at 5 points $(1=$ Never, $2=\mathrm{Up}$ to five times, $3=\mathrm{Up}$ to 10 times, $4=\mathrm{Up}$ to 20 times, and $5=$ More than 20 times).

\section{Perceived Severity of COVID-19}

This scale was developed in the scope of this research and was composed of five items. One example of an item is "I believe that if I contract COVID-19, it will bring severe detrimental consequences to my life" and "I believe that if I contract COVID-19, my health would not be significantly affected". The scale was scored at five points $(1=$ Strongly disagree, 2 $=$ Partially disagree, $3=$ Neither agree nor disagree, $4=$ Partially agree, and 5 = Strongly agree). An exploratory factor analysis indicated that the extraction of one factor explains $60.41 \%$ of the measure's total variance. Eigenvalues and parallel analysis suggested the extraction of one factor. Bartlett's test of sphericity indicated the overall significance of all the correlations within the correlation matrix for travel intentions, $\chi^{2}(1,150)=2592.07, p<0.001$. The strength of the relationships among variables was acceptable $(\mathrm{KMO}=.76)$. The Cronbach's $\alpha$ coefficient of the scale was .84 .

\section{Perceived Probability of Infection}

Three items were conceived in the scope of this research to assess participants' perceived probability of infection when traveling in 2020 and 2021. One example of an item is "I believe that if I travel in 2020 there is a high risk of contracting COVID-19". A 5-point scoring was adopted $(1=$ Strongly disagree, 2 = Partially disagree, $3=$ Neither agree nor disagree, $4=$ Partially agree, and $5=$ Strongly agree) . Exploratory factor analyzes indicated that the extraction of one factor explains $55.55 \%$ of the measure's total variance for 2020 and $57.72 \%$ for 2021. Eigenvalues and parallel analysis indicated the extraction of one factor. Bartlett's test of sphericity indicated that the overall significance of all the correlations within the correlation matrix for travel intentions in 2020, $\chi 2(1,150)=414.33, \mathrm{p}$ $<0.001$, and 2021, $\chi^{2}(1,150)=608.39, \mathrm{p}<0.001$. The strength of the relationships among variables was acceptable for $2020(\mathrm{KMO}=.58)$ and 2021(KMO $=.54)$. The Cronbach's $\alpha$ coefficient of the scales was .58 and .60 for the perceived probability of infection in 2020 and 2021, respectively.

\section{Expected Duration of COVID-19 Pandemic}

One item aimed at assessing participants' expectations about the duration of the pandemic. The answers were scored at eight points $(1=$ One month, $2=$ Two months, $3=$ Three months, $4=$ Four months, $5=$ Five months, 6 $=$ Six months, $7=$ Up to one year, and $8=$ Over one year).

\section{IUS-12 (Intolerance of Uncertainty Scale, Short Version)}

The short version of the IUS-12 (Intolerance of Uncertainty Scale) adapted by Carleton et al. (2007) was used. The scale is composed of 12 items that are grouped into two dimensions: prospective anxiety (fear and anxiety based on future events) and inhibitory anxiety (uncertainty inhibiting action or experience). It was translated from English to Brazilian Portuguese. A 5-point scoring was adopted $(1=$ Strongly disagree, $5=$ Strongly agree). The higher the score was, the stronger was the participants' uncertainty avoidance level. An exploratory factor analysis indicated that the extraction of two factors explains $52.63 \%$ of the measure's total variance. Eigenvalues and parallel analysis also indicated the extraction of two factors. Bartlett's test of sphericity indicated the overall significance of all the correlations within the correlation matrix, $\chi 2(1,150)=3441.88, p<0.001$. The strength of the relationships among variables was high $(\mathrm{KMO}=.87)$. The Cronbach's $\alpha$ coefficient of the scale was .91. The ones for prospective anxiety as well as inhibitory anxiety were both .85 . A confirmatory factor analysis 
indicated the following results: $\mathrm{CFI}=.82$, RMSEA $=.11$, $\mathrm{NFI}=.81$.

\section{Sociodemographic Measures}

Questions about income, gender, age, and educational level were applied. Income was measured in a scale ranging from "no income" to "above 20 minimum wages " 1 (1 = Up to two minimum wages, 2 = From two minimum wages to four minimum wages, $3=$ From four minimum wages to 10 minimum wages, $4=$ From 10 minimum wages to 20 wages, $5=$ Above 20 minimum wages). The current minimum wage in Brazil is $\mathrm{R} \$ 1045$, which is equivalent to US\$199.65. Gender was assessed through a closed-ended question with three options (1- Male, 2Female, 3- Other). The question about age was open-ended. As for education, participants answered a 7-point scale $(1$ = Unfinished elementary school, 2 = Finished elementary school, $3=$ Did not finish high school, $4=$ Finished high school, $5=$ Did not finish an undergraduate degree, $6=$ Finished an undergraduate degree, and 7 $=$ Post-graduation) .

\section{Procedure}

The data was collected from 5 April to 5 May 2020, when COVID-19 had already been declared a pandemic by the World Health Organization. At the beginning of the data collection, there were 1,133,758 confirmed cases worldwide and 9056 in Brazil (World Health Organization, 2020). Most European countries were under full lockdown, other countries adopted partial lockdown or national recommendations to contain the spread of the virus (BBC, 2020). Up to $56 \%$ of Brazil's population was following stay-at-home orders (Inloco, 2020).

A self-selection survey was conducted. The convenience sampling method was adopted to recruit a considerable number of participants in a short period without great resource requirements. The survey instrument was an online questionnaire that consisted of four sections: travel intentions, health risk perception, intolerance of uncertainty, and sociodemographic measures. The online questionnaire facilitated access to the sample during the period of stay-at-home orders, made it easier to reach specific interest groups - such as travelers - and was quick to disseminate and respond to (Beling et al., 2011; Whitehead, 2007).

\footnotetext{
${ }^{1}$ When this study was carried out, the minimum wage was $1.045,00 \mathrm{BRL}$ (199.65 USD).
}

Invitations to participate in the research were distributed in travel groups via a social network (Facebook), a messaging app (WhatsApp), and e-mail. The study followed the ethical guidelines of research with human subjects. The collected data were sorted in SPSS 22.

\section{Results}

When it comes to participants' travel plans for 2020, most participants $(70.76 \%, \mathrm{n}=823)$ stated that COVID-19 had affected their travel plans while $29.23 \%(n=340)$ said it had not. Out of the ones who stated to have travel plans, 749 participants answered about how the COVID-19 pandemic had affected their plans. Most of them $(56.32 \%)$ stated they had rescheduled their trip and $36.58 \%$ said they had canceled it. The remaining $7.00 \%$ reported other types of alterations. As for 2021, an even higher percentage $(81.94 \%, \mathrm{n}=953)$ reported having travel plans whereas $18.06 \%(\mathrm{n}=210)$ did not report any. Out of the ones who stated that they have travel plans for this year, 270 answered that had altered their plans. The observed intentions for 2020 were similar to the ones for 2021 , with most participants $(51.12 \%)$ indicating that they had chosen to reschedule their travels to the detriment of canceling $(11.85 \%)$ them. The remaining $37.03 \%$ reported other types of alterations. These results confronted our expectations that - since Brazil consists of a culture with a high score in the cultural value of uncertainty avoidance - Brazilians would tend to opt for canceling their trips instead of postponing them.

One model has been proposed to predict travel intentions for 2020 and 2021 (see Fig. 1). In order to assess whether the antecedent variables in our model (IU, perceived severity of COVID-19, perceived probability of infection, and expected duration of the pandemic) explain a significant proportion of the variance of the criterion variable (either travel intentions for 2020 or 2021) even when accounting for the effects of the control variables (monthly income, age, educational level, international travel experience), we have conducted two stepwise multiple regressions. When performing these analyzes, we inserted the sociodemographic variables in the first step and the antecedent variables in the second step. By doing so, we have observed that the coefficient of determination $\left(\mathrm{R}^{2}\right)$ has improved significantly. In Model I, it has risen from .01 to .13. In Model II, it has increased from .05 to .14. We evaluated the assumptions of multivariate normality and linearity by using SPSS 22. Through the observation of box plots and the calculation of the Mahalanobis distance, we have spotted 
Fig. 1 Model of travel intentions prediction

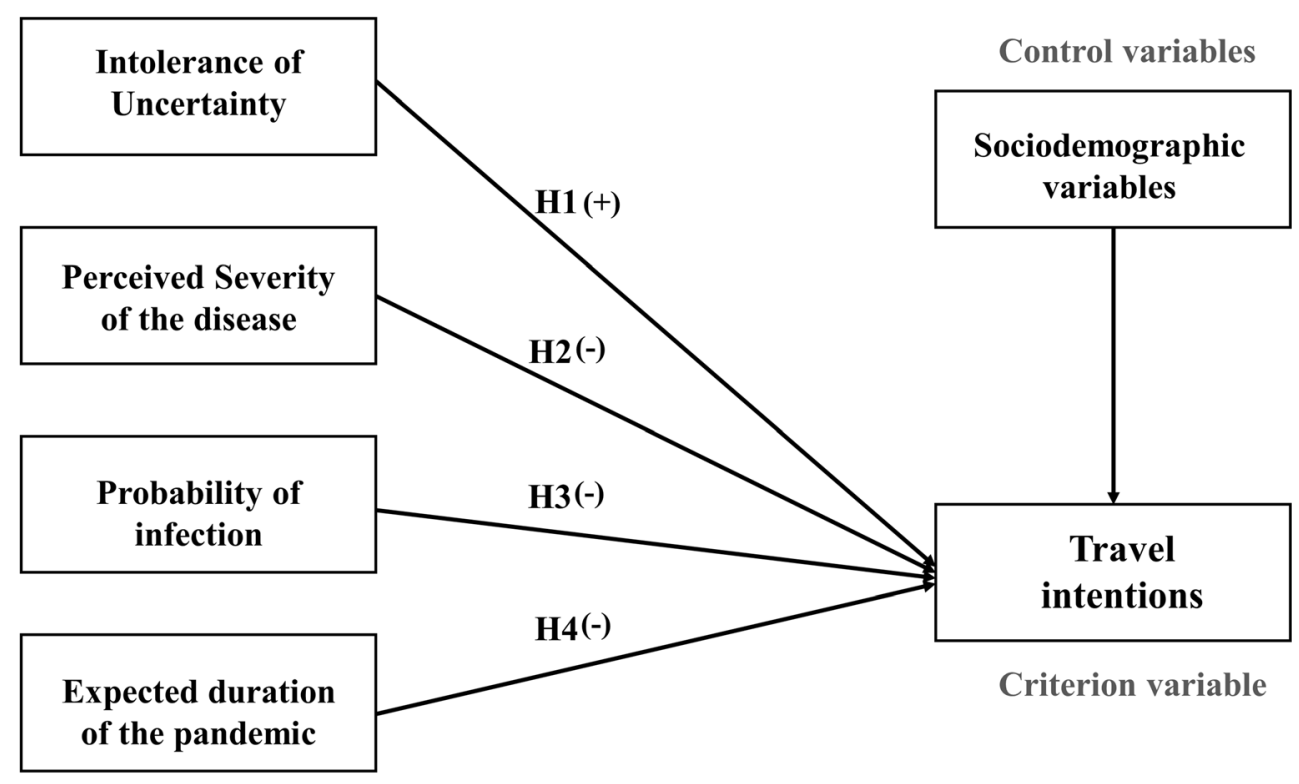

Antecedent variables
13 multivariate outliers, which have been removed from the sample.

As for intentions of traveling in 2020 and 2021, Hypothesis 1 has been rejected while Hypotheses 2 to 4 have been accepted. That is, IU is not a significant predictor of traveling in 2020 and 2021 whereas perceived severity of COVID-19, perceived probability of infection, and perceived duration of the pandemic significantly predict travel intentions for both years. Check Appendix Table 2 for bivariate correlations among all variables and multiple regression analyzes of the proposed models.

We have also conducted exploratory moderation analyzes using the PROCESS macro (Hayes, 2012) to evaluate whether the control variables (income, gender, age, education level, and international travel experience) could affect the relationship between antecedent (IU, perceived severity of the disease, probability of infection, and expected duration of the pandemic) and criterion variables (travel intentions for 2020 and 2021). The lower the perceived probability of infection and the higher the income, the stronger are travel intentions for 2020, F $(1146,3)=$ $40.20, \mathrm{t}(1146)=-2.31, \mathrm{~b}=-.03, \mathrm{p}=.02, \mathrm{R}^{2}=.10$, $95 \%$ CI $[-.11,-.009]$. Besides, age has moderated the effect of probability of infection on travel intentions for 2020, $\mathrm{F}(1146,3)=44.76, \mathrm{t}(1146)=-3.75, \mathrm{~b}=-.009$, $\mathrm{p}=.0002, \mathrm{R}^{2}=.10,95 \% \mathrm{CI}[-.05,-.008]$, in that the higher the age and the lower the risk perception, the stronger are travel intentions. Income also moderates the effect of the perceived duration of the pandemic on travel intentions, $\mathrm{F}(1146,3)=28.17, \mathrm{t}(1146)=-2.74, \mathrm{~b}=-.03, \mathrm{p}$
$=.006, \mathrm{R}^{2}=.07,95 \%$ CI $[-.05,-.008]$. That is, the higher the income and the shorter the perceived duration of the pandemic, the stronger are travel intentions for 2020 .

Furthermore, we have found a significant effect of international travel experience on the relationship between expected duration of the pandemic and travel intentions for 2020, $\mathrm{F}(1146,3)=26.51, \mathrm{t}(1150)=-2.06, \mathrm{~b}=-.02, \mathrm{p}=$ $.04, \mathrm{R}^{2}=.06,95 \% \mathrm{CI}[-.05,-.001]$. It means that holding more international travel experience and expecting the pandemic to last for a shorter period are significant predictors of stronger travel intentions. Finally, income has been found to moderate the effect of perceived severity of the disease on travel intentions for 2021, F $(1146,3)=$ 27.04, $\mathrm{t}(1150)=-2.18, \mathrm{~b}=-.04, \mathrm{p}=.03, \mathrm{R}^{2}=.07$, $95 \%$ CI $[-.08,-.004]$, in that the lower the perceived severity of COVID-19 and the higher the income, the stronger are travel intentions. No other significant moderations have been found.

\section{Discussion}

In this study, we aimed at assessing variables related to the COVID-19 pandemic that have an impact on travel plans. Specifically, this study assessed the effect of uncertainty, health risk perceptions (severity of COVID-19 and likelihood of contracting it), and perceived duration of the outbreak on Brazilians' travel intentions for the years 2020 and 2021. We have also controlled for the impact of individual variables 
(travel experience, age, educational level, and income) on these intentions.

Considering that Brazil ranks high on UA (Hofstede Insights, n.d.) and thus is expected to have a large number of uncertainty-intolerant individuals, we expected that participants would be more prone to cancel their trips to avoid waiting in the state of uncertainty. However, we found that Brazilians tended to reschedule their trips during uncertain times to the detriment of canceling them. The prospect theory - a psychological theory which states that individuals are generally risk-seeking when dealing with possible losses but risk-averse when dealing with gains (Kahneman \& Tversky, 1979; Tversky \& Kahneman, 1992) - provides a plausible explanation for these unexpected results. According to this theory, people tend to accept running more risks to avoid possible losses if compared to running risks to obtain potential gains. While rescheduling trips is usually free of charges, cancellations frequently require that high fees be discounted from the amount to be reimbursed, which incur losses to travelers. Therefore, participants may have opted for a riskier decision (rescheduling), besides other reasons, to avoid paying cancellation fees as well as because individuals tend to prefer future gains and losses when the present is not certain (Hardisty \& Pfeffer, 2016). Since the pandemic is uncertain, individuals may have tended to opt for postponing their travels to avoid immediate losses represented by the fees charged by the air companies and tourism agencies.

Even though high IU was positively associated with perceiving the pandemic as more severe and perceiving a higher probability of infection, we did not find IU to be a significant predictor of travel intentions for both 2020 and 2021, which contradicts our expectations. Therefore, it appears like IU levels do not directly affect travel intentions. Conversely, health risk variables (perceived severity of the disease and probability of infection) have been found to be the significant predictors of weaker travel intentions for both 2020 and 2021, which is in line with previous research (Das \& Tiwari, 2020; Huang et al., 2020; Li et al., 2020; Neuburger \& Egger, 2020; Provost \& Soto, 2002). These results are also consistent with the findings that health risks have a significant effect on traveler behavior (Chien et al., 2017; Kozak et al., 2007; McKercher \& Chon, 2004; Neuburger \& Egger, 2020; Novelli et al., 2018; Rittichainuwat \& Chakraborty, 2009; Sönmez \& Graefe, 1998b) and that individuals who perceive higher susceptibility to health risks and severity of diseases can become more prone to adopt health-preventative behaviors, which include avoiding traveling (Brewer et al., 2007; Chapman \& Skinner, 2008; Huang et al., 2020; Das \& Tiwari, 2020). Besides being positively related to perceived severity of COVID-19 and perceived probability of infection in 2020 and 2021, the expected duration of the pandemic has also held a significant negative impact on travel intentions for both years. This result is aligned with the reports that the expected timeline of an epidemic was linked with avoidance behaviors (Rubin et al., 2009) and that expected outbreak duration is a remarkable predictor of tourist behavior (Li et al., 2020).

In this research, we have controlled for the impact of individual characteristics on Brazilians' travel intentions. We discovered supporting evidence for holding that in post-crisis times of lower uncertainty, represented by 2021 in this study - since $66,80 \%$ of participants believed that the pandemic would last up to six months, that is, until September-October 2020 -, travel experience and income are significant predictors of travel intentions. In this vein, we have found that individuals who have more international travel experience and expect the pandemic to last for a shorter period tend to have stronger travel intentions for 2020. As reported by several studies (Floyd et al., 2004; Kozak et al., 2007; Neuburger \& Egger, 2020; Polas et al., 2019; Reza \& Samiei, 2012; Sönmez \& Graefe, 1998b), tourists with more extensive travel experience are more likely to travel in risky situations. This may be the case because, as found in our research, the more extensive travel experience is related to having lower intolerance of uncertainty, perceiving the disease as less severe, and believing that there is a lower probability of being infected.

Travel experience and income have presented a strong positive relationship. In fact, we have found that income has positively affected travel intentions for 2021. We have also discovered that people with higher income also tend to be more intolerant of uncertainty, perceive less severity of COVID-19, and have more extensive travel experience. Additionally, we found an interaction effect between the perception of risk and income in that individuals with lower risk perception and higher income tend to hold stronger travel intentions for 2020. Besides, people with higher income and who perceive the pandemic to last for a shorter period are more prone to hold stronger travel intentions for this year. Lower perceived severity of COVID-19 and higher income also account for stronger travel intentions for 2021. All these findings are aligned with the reports that income levels predict tourist decisions in risky and riskless contexts (Sönmez \& Graefe, 1998b; Li et al., 2018; Djeri et al., 2014).

As to the effect of educational level on travel intentions for 2021, our results contradict the reports that individuals with higher educational levels tend to travel more in risky situations (Qi et al., 2009; Sönmez \& Graefe, 1998b). We have actually found the opposite trend. Furthermore, the interaction between being less intolerant of uncertainty 
and holding a lower level of education indicated stronger travel intentions. Correlation analysis indicated a positive relationship between the level of education and the expected duration of the pandemic, suggesting that more educated individuals tend to expect the pandemic to last longer. We assume that this may be the case because people who are more educated tend to have more positive attitudes towards science (Evans \& Durant, 1995; Hayes \& Tariq, 2000; Pardo \& Calvo, 2004; Allum et al., 2008). By considering the scientific evidence, these individuals may have predicted that the pandemic would still be taking place in 2021 and therefore have weaker intentions of traveling this year.

We did not find a significant sole effect of age as a predictor of travel intentions for both years. Nonetheless, we found an interaction effect in which holding less severe COVID-19 perceptions and being older indicated stronger travel intentions for 2020 . These results are partly in line with Neuburger and Egger (2020), who found that older individuals with more travel experience and lower COVID-19 risk perception were not likely to avoid traveling. However, our findings do not support other previous studies pointing out that older tourists show a decreased intention of taking trips due to a disease outbreak (Das \& Tiwari, 2020; Senbeto \& Hon, 2020). Our results actually contradict the report that younger tourists are more likely to travel in the face of risks in comparison with older ones (Gibson \& Yiannakis, 2002; Williams \& Baláž, 2013). Our findings are unexpected since older individuals are more at risk of developing more severe symptoms of COVID-19 (Kluge, 2020). It is also worth highlighting that correlation analyzes pointed out that, besides perceiving fewer health risks in 2020 , older individuals tend to be less intolerant of uncertainty and hold higher incomes.

\section{Conclusion}

To the best of our knowledge, this is the first multivariate study to evaluate the travel intentions of Brazilians during the COVID-19 pandemic. Our findings have implications for tourism practitioners and authorities because it allows tracing the traveler profile that can help destinations to recover faster. Since Brazil ranks among the 20 countries with the greatest international tourism expenditures (The World Bank, 2020), it is important to comprehend the behavior of Brazilian tourists during health crises. We have gone some way towards deepening the understanding of tourist behavior during health crises, in particular, the COVID-19 pandemic. Given the need for more interdisciplinary research that could provide practical solutions in the context of the COVID-19 crisis (Wen et al., 2020), our study offers insights on public and private recovery strategies for the tourism industry.

\section{Theoretical and Practical Implications}

This study contributed to deepening the discussion on tourist behavior in the context of health risks. Our results are in line with previous research on COVID-19, carried out in European and Asian countries, showing that health risk-related variables are strong predictors of travel intentions. This reinforces the importance for tourism scholars to conduct interdisciplinary research, especially with psychology colleagues, to successfully understand psychological processes that underlie traveler behavior during health crises. In our research, we addressed the influence of factors that have been already mentioned in the tourism literature - such as age, income, travel experience, education level, on travel intentions - during a pandemic period. This could provide a deeper understanding of crisisresistant tourists' characteristics. It is also worth highlighting that most of the claims about human behavior are based on samples taken entirely from western, educated, industrialized, rich, and democratic (WEIRD) societies (Henrich et al., 2010). However, behavioral patterns which are typical from WEIRD societies may not be found in non-WEIRD ones. To the best of our knowledge, this is the first study to analyze travel intentions during a health crisis carried out in Brazil, a nonWEIRD society.

This study has revealed that health risk perception variables, namely perceived severity of the COVID-19, probability of contracting it, and expected duration of the pandemic were the most influential factors on weaker travel intentions for 2020 and 2021. We, therefore, provided evidence of the relevance of adopting health risk prevention measures in tourist destinations to increase travel intentions. Besides, working towards engaging in effective communication practices along with providing transparent and easily accessible information can make individuals feel safer to travel and make tourists more comfortable to resume tourism activities. Travel experience and income also appear to be relevant in the period perceived by participants as post-crisis (the year 2021). By considering this information, the tourism industry is advised to focus on travelers of high income in the post-pandemic period, considering the economic instability that is already affecting or will affect most of the Brazilian population. Highly educated individuals, however, seem to be prone not to travel during the pandemic as well as in a recent post-pandemic period. Another contribution consisted of providing information about how actual travel plans for the years 2020 and 2021 have been affected by the pandemic. By bearing this data in mind, it is 
possible to draw a clearer picture of the impact of COVID-19 on individuals' travel plans and preparing recovery strategies.

\section{Limitations and Future Research}

This research has a number of limitations. The sample is skewed in terms of gender $(70.33 \%$ were female) and education $(51.16 \%$ were either postgraduate students or had a postgraduate degree). Nevertheless, these limitations reflect the convenience sampling nature of our data collection, which made it impossible to acquire a sample that reflects the same features of the Brazilian population in a similar proportion. We, therefore, suggest that future research be conducted to replicate our research design with a sample that is more balanced in terms of the Brazilian population features to verify whether our results will stand.

Furthermore, the research was carried out at the beginning of the COVID-19 outbreak in Brazil (from early April to early May 2020). This temporal component may have influenced the results. Therefore, further research should be conducted in other phases of the pandemic. Besides, based on our findings, we suggest that future studies delve into the effect of attitude toward science - as well as interaction effects with sociodemographic variables such as income, age, and level of education - on travel intentions, especially in the face of health risks.

When it comes to the measures applied, there was not a validated translation of the measure IUS to Brazilian Portuguese at the time the study was conducted. We performed the translation, however, due to time restrictions, we did not perform back translation. Whereas an exploratory factor analysis indicated that the strength of the relationships among variables was high and that there was high reliability, a confirmatory factor analysis did not indicate good construct validity. Therefore, future research on IU should use a validated translation to measure. It is also important to highlight that the newly developed measures applied in this research have not been validated and their reliability has not been tested. Additional studies may be carried out in the future to address face validity and assess test-retest reliability.

Another limitation lies in the fact that we performed a large number of moderator analyses, which could have inflated Type I errors and lead to chance findings. For this reason, the results of the moderation analyses should be cautiously interpreted, and future research to assess whether the results found are replicable is highly recommended. Besides, some of the findings on which we have based our hypothesis have not been replicated in our research, for instance, the relationship between age and travel intentions. The reason for these opposing results may also lie in the nature of our sample. Therefore, we strongly suggest that further studies be conducted in other non-WEIRD countries to check whether these contrasting findings may be a result of cultural differences. Conducting cross-cultural as well multidisciplinary research on the effect of health risks and uncertainty on traveler behavior is essential to obtain accurate comprehension of the impact of health crises on the tourism sector and to contribute to being more prepared to overcome the challenges posed by pandemics that may arise in the future.

\section{Appendix 1}

Table 1 Sociodemographic characteristics and travel experience of the sample $(n=1150)$

\begin{tabular}{|c|c|c|c|}
\hline & & $n$ & $\%$ \\
\hline Gender & $\begin{array}{l}\text { female } \\
\text { male } \\
\text { other }\end{array}$ & $\begin{array}{l}810 \\
331 \\
9\end{array}$ & $\begin{array}{l}70.43 \\
28.78 \\
0.78\end{array}$ \\
\hline Age & $\begin{array}{l}18-25 \\
26-33 \\
34-41 \\
42-49 \\
50-57 \\
58-65 \\
66 \text { and above }\end{array}$ & $\begin{array}{l}148 \\
292 \\
293 \\
152 \\
151 \\
87 \\
27\end{array}$ & $\begin{array}{l}12.86 \\
25.39 \\
25.47 \\
13.21 \\
13.13 \\
7.56 \\
2.34\end{array}$ \\
\hline Education & $\begin{array}{l}\text { incomplete high } \\
\text { school } \\
\text { completed high } \\
\text { school } \\
\text { incomplete } \\
\text { university degree } \\
\text { completed university } \\
\text { degree } \\
\text { postgraduate degree }\end{array}$ & $\begin{array}{l}1 \\
28 \\
142 \\
387 \\
591\end{array}$ & $\begin{array}{l}0.08 \\
2.43 \\
12.34 \\
33.65 \\
51.39\end{array}$ \\
\hline Monthly income & $\begin{array}{l}\text { up to } 2 \mathrm{MW} * \\
2-4 \mathrm{MW} \\
4-10 \mathrm{MW} \\
10-20 \mathrm{MW} \\
\text { above } 20 \mathrm{MW}\end{array}$ & $\begin{array}{l}161 \\
239 \\
354 \\
226 \\
170\end{array}$ & $\begin{array}{l}14.00 \\
20.78 \\
30.78 \\
19.65 \\
14.78\end{array}$ \\
\hline $\begin{array}{l}\text { Domestic travel experience in the } \\
\text { last } 5 \text { years }\end{array}$ & $\begin{array}{l}0 \text { trips } \\
1-5 \text { trips } \\
6-10 \text { trips } \\
11-20 \text { trips } \\
\text { more than } 20 \text { trips }\end{array}$ & $\begin{array}{l}47 \\
267 \\
236 \\
168 \\
432\end{array}$ & $\begin{array}{l}4.08 \\
23.21 \\
20.52 \\
14.60 \\
37.56\end{array}$ \\
\hline $\begin{array}{l}\text { International travel experience in the } \\
\text { last } 5 \text { years }\end{array}$ & $\begin{array}{l}0 \text { trips } \\
1-5 \text { trips } \\
6-10 \text { trips } \\
11-20 \text { trips } \\
\text { more than } 20 \text { trips }\end{array}$ & $\begin{array}{l}255 \\
500 \\
207 \\
116 \\
72\end{array}$ & $\begin{array}{l}22.17 \\
43.47 \\
18.00 \\
10.08 \\
6.26\end{array}$ \\
\hline
\end{tabular}

${ }^{*} M W$ minimum wage, $1 \mathrm{MW}=199.65 \mathrm{USD}$ 


\section{Appendix 2}

Table 2 Summary of simple regression analyzes and bivariate correlations for Travel Intentions for 2020 and 2021 as criterion variables and Intolerance of Uncertainty, Perceived Severity of the
Disease, Probability of Infection, and Expected Pandemic Duration, as antecedents. International Travel Experience, Monthly Income, Age, and Educational Level have been inserted as control variables $(N=1150)$

\begin{tabular}{|c|c|c|c|c|c|c|c|c|c|c|c|c|c|}
\hline Variables & $\mathrm{IU}$ & Sev & Pro20 & Pro21 & Dur & Exp & Inc & Age & Edu & Int20 & Int 21 & $\begin{array}{l}\text { Model I Int20 } \\
\beta[\mathrm{B} 95 \% \mathrm{CI}]\end{array}$ & $\begin{array}{l}\text { Model II Int21 } \\
\beta \text { [B 95\% CI] }\end{array}$ \\
\hline $\mathrm{IU}$ & - & & & & & & & & & & & $-.04[-.13, .02]$ & $.02[-.04, .09]$ \\
\hline Sev & $.15+$ & - & & & & & & & & & & $-.06 *[-.12,-.001]$ & $-.08 *[-.12,-.02]$ \\
\hline Pro20 & $.10^{*}$ & $.38+$ & - & & & & & & & & & $-.22+[-.32,-.18]$ & - \\
\hline Pro21 & $.08^{*}$ & $.31+$ & $.47+$ & - & & & & & & & & - & $-.19+[-.27,-.14]$ \\
\hline Dur & .003 & $.21+$ & $.32+$ & $.30+$ & - & & & & & & & $-.15+[-.10,-.05]$ & $-.13+[-.08,-.03]$ \\
\hline Exp & $-.08 *$ & $-.18+$ & -.02 & $-.08 *$ & .01 & - & & & & & & $.03[-.03, .08]$ & $.15^{*}[.06, .16]$ \\
\hline Inc & $-.12+$ & $-.15+$ & -.02 & $-.06^{*}$ & .04 & $.52+$ & - & & & & & $-.05[-.09, .01]$ & $.09 *[.02, .11]$ \\
\hline Age & $-.13+$ & -.01 & $-.11+$ & -.02 & -.05 & .03 & $.25+$ & - & & & & $-.02[-.006, .003]$ & $-.02[-.005, .003]$ \\
\hline Edu & $-.12+$ & -.03 & .05 & .003 & $.08^{*}$ & $.18+$ & $.28+$ & $.15+$ & - & & & $-.06 *[-.15,-.007]$ & $-.03[-.10, .03]$ \\
\hline Int20 & $-.06^{*}$ & $-.19+$ & $-.30+$ & $-.17+$ & $-.25+$ & .008 & -.05 & -.001 & $-.09+$ & - & & & \\
\hline Int21 & -.04 & $-.20+$ & $-.17+$ & $-.27+$ & $-.20+$ & $.21+$ & $.17+$ & .01 & .003 & $.27+$ & - & & \\
\hline Mean & 3.30 & 3.57 & 3.62 & 2.85 & 4.94 & 2.35 & 3.00 & 39.22 & 6.34 & 2.60 & 3.88 & & \\
\hline SD & .74 & .98 & .86 & .83 & 2.06 & 1.12 & 1.25 & 12.43 & .79 & .97 & .87 & & \\
\hline $\mathrm{R}^{2}$ & & & & & & & & & & & & .13 & .14 \\
\hline Adj $R^{2}$ & & & & & & & & & & & & .12 & .13 \\
\hline $\mathrm{F}$ & & & & & & & & & & & & 21.17 & 23.54 \\
\hline
\end{tabular}

IU Intolerance of uncertainty, Sev Perceived Severity of the Disease, Pro20 Probability of Infection in 2020, Pro21 Probability of Infection in 2021, Dur Expected Duration of the Pandemic, Exp International Travel Experience, Inc. Monthly Income, Age Age, Edu Educational Level, Int20 Travel Intentions for 2020; and Int21 Travel Intentions for 2021

$+p<.001, * p<.05$

Acknowledgements We thank the Brazilian Ministry of Tourism and the Brazilian Tour Operators Association (Braztoa) for their support in data collection.

Availability of Data and Material The dataset for this study can be found in the OSF platform on the link https://osf.io/hgp7y/. Once the manuscript is published, the files will be made public.

Code Availability Not applicable.

Authors' Contributions The first, the second and the third authors contributed to the conception and design of the study. The first and the second authors collected the raw data, and the first author organized the database. The second author performed statistical analyses. The first and the second authors wrote the first draft of the manuscript. The third and the fourth authors revised it critically for important intellectual content.

Funding This work was partly supported by the Coordination for the Improvement of Higher Education Personnel (CAPES) under Scholarship number 88887.356876/2019-00; and the National Council for Scientific and Technological Development (CNPq) under Grant number 308268/2016-4.

\section{Declarations}

Ethics Approval The study reported in the manuscript strictly followed the Ethical Principles in the Conduct of Research with Human Participants proposed by the American Psychological Association. Participants were informed about the research purposes, the risks involved in taking part of the research, as well as the confidentiality and anonymity of the participation. The research protocol was not submitted to an approving institutional review board because the committee's rules and regulations in Brazil only evaluate projects in the realm of medical and pharmacological research. Considering this situation regarding the current national regulations, it is not required to obtain approval from an institutional review board to conduct studies with human subjects in social and behavioural sciences.

Consent to Participate Participants explicitly informed their consent in taking part in the research by checking a box and were free to quit participation at any moment. No personal information was collected to preserve participants' anonymity.

Consent for Publication All data collected were unidentified and analysed in a grouped manner so that each participant who answered the research is anonymous. Informed consent on the academic purpose data collection was obtained from all individual participants.

Conflicts of Interest The authors declare that the research was conducted in the absence of any commercial or financial relationships that could 
be construed as a potential conflict of interest. We have no known conflict of interest to disclosure.

\section{References}

Adeloye, D., \& Brown, L. (2017). Terrorism and domestic tourist risk perceptions. Journal of Tourism and Cultural Change, 16(3), 217233. https://doi.org/10.1080/14766825.2017.1304399

Allum, N., Sturgis, P., Tabourazi, D., \& Brunton-Smith, I. (2008). Science knowledge and attitudes across cultures: A meta-analysis. Public Understanding of Science, 17(1), 35-54. https://doi.org/10. 1177/0963662506070159

Aschauer, W. (2010). Perceptions of tourists at risky destinations. A model of psychological influence factors. Tourism Review, 65(2), 4-20. https://doi.org/10.1108/16605371011061589

BBC (2020). Coronavirus: The world in lockdown in maps and charts. Retrieved May 3, 2020, from https://www.bbc.com/news/world52103747.

Bedford, J., Farrar, J., Ihekweazu, C., Kang, G., Koopmans, M., \& Nkengasong, J. (2019). A new twenty-first century science for effective epidemic response. Nature, 575(7781), 130-136. https://doi. org/10.1038/s41586-019-1717-y

Beling, J., Libertini, L. S., Sun, Z., Masina, V. M., \& Albert, N. M. (2011). Predictors for electronic survey completion in healthcare research. CIN: Computers, Informatics, Nursing, 29(5), 297-301. https://doi.org/10.1097/ncn.0b013e3182065fbb

Brewer, N. T., Chapman, G. B., Gibbons, F. X., Gerrard, M., McCaul, K. D., \& Weinstein, N. D. (2007). Meta-analysis of the relationship between risk perception and health behavior: The example of vaccination. Health Psychology, 26(2), 136-145. https://doi.org/10. 1037/0278-6133.26.2.136

Carleton, R. N., Norton, M. A. P. J., \& Asmundson, G. J. G. (2007). Fearing the unknown: A short version of the intolerance of uncertainty scale. Journal of Anxiety Disorders, 21(1), 105-117. https:// doi.org/10.1016/j.janxdis.2006.03.014

Carleton, R. N., Duranceau, S., Shulman, E. P., Zerff, M., Gonzales, J., \& Mishra, S. (2016). Self-reported intolerance of uncertainty and behavioral decisions. Journal of Behavior Therapy and Experimental Psychiatry, 51, 58-65. https://doi.org/10.1016/j.jbtep.2015.12.004

Casidy, R., \& Wymer, W. (2016). A risk worth taking: Perceived risk as moderator of satisfaction, loyalty, and willingnessto-pay premium price. Journal of Retailing and Consumer Services, 32, 189-197. https://doi.org/10.1016/j.jretconser.2016.06.014

Chahal, H., \& Devi, A. (2017). How perceived risk influences image and loyalty relationship in a tourist destination? An Indian perspective. International Journal of Leisure and Tourism Marketing, 5(2), 100. https://doi.org/10.1504/ijltm.2017.084618

Champion, V. L., \& Skinner, C. S. (2008). The health belief model. Health behavior and health education: Theory, research, and practice, 4, 45-65.

Chen, Y. Q., \& Zhang, H. (2012). Investigation of sports tourism visitors risk perception and coping behavior. Journal of Hebei Institute of Physical Education, 26(3), 38-43.

Chew, E. Y. T., \& Jahari, S. A. (2014). Destination image as a mediator between perceived risks and revisit intention: A case of post-disaster Japan. Tourism Management, 40, 382-393. https://doi.org/10.1016/ j.tourman.2013.07.008

Chien, P. M., Sharifpour, M., Ritchie, B. W., \& Watson, B. (2017). Travelers' health risk perceptions and preventative behavior: A psychological approach. Journal of Travel Research, 56(6), 744-759. https://doi.org/10.1177/0047287516665479

CNC [National Confederation of Trade in Goods, Services and Tourism] (2019). O bom desempenho do emprego no turismo em outubro de 2019. Retrieved May 19, 2020, from http://www.cnc.org.br/sites/
default/files/2019-12/An\%C3\%A1lise_Empregabilidade\%20no\% 20Turismo_Outubro_2019.pdf

Crotts, J. C. (2004). The effect of cultural distance on overseas travel behaviors. Journal of Travel Research, 43(1), 83-88. https://doi. org/10.1177/0047287504265516

Das, S. S., \& Tiwari, A. K. (2020). Understanding international and domestic travel intention of Indian travelers during COVID-19 using a Bayesian approach. Tourism Recreation Research, 46, 117. https://doi.org/10.1080/02508281.2020.1830341

Djeri, L., Armenski, T., Jovanović, T., \& Dragin, A. (2014). How income influences the choice of tourism destination?. Acta Oeconomica, 64(2), 219-237.

Evans, G., \& Durant, J. (1995). The relationship between knowledge and attitudes in the public understanding of science in Britain. Public Understanding of Science, 4(1), 57-74. https://doi.org/10.1088/ 0963-6625/4/1/004

FGV [Getúlio Vargas Foundation] (2020). Centro de Estudos em Competitividade da FGV/EBAPE. Impacto econômico do COVID-19. Propostas para o turismo brasileiro. Retrieved May 15, 2020, from https://fgvprojetos.fgv.br/sites/fgvprojetos.fgv.br/ files/01.covid19_impactoeconomico_v09_compressed_1.pdf

Floyd, D. L., Prentice-Dunn, S., \& Rogers, R. W. (2000). A meta-analysis of research on protection motivation theory. Journal of Applied Social Psychology, 30(2), 407-429. https://doi.org/10.1111/j.15591816.2000.tb02323.x

Floyd, M. F., Gibson, H., Pennington-Gray, L., \& Thapa, B. (2004). The effect of risk perceptions on intentions to travel in the aftermath of September 11, 2001. Journal of Travel \& Tourism Marketing, 15(2/3), 19-38. https://doi.org/10.1300/J073v15n02_02

Gibson, H., \& Yiannakis, A. (2002). Tourist roles: Needs and the adult life course. Annals of Tourism Research, 2, 358-383. https://doi.org/ 10.1016/s0160-7383(01)00037-8

Graburn, N. H. H. (1983). The anthropology of tourism. Annals of Tourism Research, 10(1), 9-33. https://doi.org/10.1016/01607383(83)90113-5

Grupe, D. W., \& Nitschke, J. B. (2013). Uncertainty and anticipation in anxiety: An integrated neurobiological and psychological perspective. Nature Reviews, 14, 488-501. https://doi.org/10.1038/nrn3524

Hajibaba, H., Gretzel, U., Leisch, F., \& Dolnicar, S. (2015). Crisisresistant tourists. Annals of Tourism Research, 53, 46-60. https:// doi.org/10.1016/j.annals.2015.04.001

Hamer, D. H., \& Connor Bradley, A. (2004). Travel health knowledge, attitudes and practices among United States travelers. Journal of Travel Medicine, 11(1), 23-26. https://doi.org/10.2310/7060.2004. 13577

Hardisty, D. J., \& Pfeffer, J. (2016). Intertemporal uncertainty avoidance: When the future is uncertain, people prefer the present, and when the present is uncertain, people prefer the future. Management Science, 63(2), 519-527. https://doi.org/10.1287/mnsc.2015.2349

Hayes, A. F. (2012). PROCESS: A versatile computational tool for observed variable mediation, moderation, and conditional process modeling [white paper]. Retrieved June, 2021, http://www. afhayes.com/public/process2012.pdf.

Hayes, B. C., \& Tariq, V. N. (2000). Gender differences in scientific knowledge and attitudes toward science: A comparative study of four Anglo-American nations. Public Understanding of Science, 9(4), 433-447. https://doi.org/10.1088/0963-6625/9/4/306

Henrich, J., Heine, S. J., \& Norenzayan, A. (2010). The weirdest people in the world? The Behavioral and Brain Sciences, 33(2-3), 61-135. https://doi.org/10.1017/S0140525X0999152X

Hofstede Insights. (n.d.). Country comparison. Brazil. Retrieved May 8 , 2020, from https://www.hofstede-insights.com/countrycomparison/brazil/.

Hofstede, G., Hofstede, G. J., \& Minkov, M. (2010). Cultures and organizations: Software of the mind. McGraw Hill. 
Huang, X., Dai, S., \& Xu, H. (2020). Predicting tourists' health risk preventative behavior and travelling satisfaction in Tibet: Combining the theory of planned behavior and health belief model. Tourism Management Perspectives, 33, 100589. https://doi.org/10. 1016/j.tmp.2019.100589

Inloco (2020). Mapa brasileiro da COVID-19. Retrieved April 5, 2020, from https://mapabrasileirodacovid.inloco.com.br/pt.

Janz, N. K., \& Becker, M. H. (1984). The health belief model: A decade later. Health Education Quarterly, 11(1), 1-47. https://doi.org/10. 1177/109019818401100101

Jonas, A., Mansfeld, Y., Paz, S., \& Potasman, I. (2010). Determinants of health risk perception among low-risk-taking tourists traveling to developing countries. Journal of Travel Research, 50(1), 87-99. https://doi.org/10.1177/0047287509355323.

Jones, C. L., Jensen, J. D., Scherr, C. L., Brown, N. R., Christy, K., \& Weaver, J. (2014). The health belief model as an explanatory framework in communication research: Exploring parallel, serial, and moderated mediation. Health Communication, 30(6), 566-576. https://doi.org/10.1080/10410236.2013.873363

Kahneman, D., \& Tversky, A. (1979). On the interpretation of intuitive probability: A reply to Jonathan Cohen. Cognition, 7(4), 409-411. https://doi.org/10.1016/0010-0277(79)90024-6

Khan, M. J., Chelliah, S., \& Ahmed, S. (2018). Intention to visit India among potential travelers: Role of travel motivation, perceived travel risks, and travel constraints. Tourism and Hospitality Research, 19(3), 351-367. https://doi.org/10.1177/1467358417751025

Kluge, H. H. P. (2020). Statement-Older people are at highest risk from COVID-19, but all must act to prevent community spread. World Health Organization (WHO). Retrieved August 1, 2020, from https://www.euro.who.int/en/health-topics/health-emergencies/ coronavirus-covid-19/statements/statement-older-people-are-athighest-risk-from-covid-19,-but-all-must-act-to-preventcommunity-spread.

Kozak, M., Crotts, J. C., \& Law, R. (2007). The impact of the perception of risk on international travelers. International Journal of Tourism Research, 9, 233-242. https://doi.org/10.1002/jtr.607

Lehto, X., Douglas, A. C., \& Park, J. (2008). Mediating the effects of natural disasters on travel intention. Journal of Travel \& Tourism Marketing, 23(2-4), 29-43. https://doi.org/10.1300/j073v23n02 03

Li, W., Mengdie, X., \& Cheng, L. (2018). Study on Behavioral Decisionmaking Based on Sunk Costs in Travel. Proceedings of the 5th International Conference on Business, Economics and Management (BUSEM 2018). Yinchuan, China. https://doi.org/10. 25236/busem.2018.031.

Li, J., Nguyen, T. H. H., \& Coca-Stefaniak, J. A. (2020). Coronavirus impacts on post-pandemic planned travel behaviors. Annals of Tourism Research. In press, 86, 102964. https://doi.org/10.1016/j. annals.2020.102964

Litvin, S. W., Crotts, J. C., \& Hefner, F. L. (2004). Cross-cultural tourist behavior: A replication and extension involving Hofstede's uncertainty avoidance dimension. International Journal of Tourism Research, 6, 29-37. https://doi.org/10.1002/jtr.468

Liu, J., \& Gao, J. (2008). Based tourism risk perception conceptual modelA case study of Shanghai residents. Tourism Science, 22(5), 37-43.

Liu, M., Brock, J., Shi, G., Chu, R., \& Tseng, T. (2013). Perceived benefits, perceived risk, and trust: Influences on consumers' group buying behavior. Asia Pacific Journal of Marketing and Logistics, 25(2), 225-248. https://doi.org/10.1108/13555851311314031

Lopez-Velez, R., \& Bayas, J. M. (2007). Spanish travelers to high-risk areas in the tropics: Airport survey of travel health knowledge, attitudes, and practices in vaccination and malaria prevention. Journal of Travel Medicine, 14(5), 297-305. https://doi.org/10.1111/j.17088305.2007.00142.x

March, R., \& Woodside, A. G. (2005). Tourism behaviour: Travellers' decisions and actions. CABI.
McKercher, B., \& Chon, K. (2004). The over-reaction to SARS and the collapse of Asian tourism. Annals of Tourism Research, 31(3), 716 719. https://doi.org/10.1016/j.annals.2003.11.002

Ministério do Turismo [Ministry of Tourism] (2020). Relatório de impacto da pandemia de COVID-19 nos setores de turismo e cultura no Brasil. Retrieved November 7, 2020, from http://www. dadosefatos.turismo.gov.br/boletins/item/download/1175 000 cfb701ec1 f89133455ce5f0ed9caa.html

Minnaert, L. (2014). Social tourism participation: The role of tourism inexperience and uncertainty. Tourism Management, 40, 282-289. https://doi.org/10.1016/j.tourman.2013.07.002

Mizrachi, I., \& Fuchs, G. (2016). Should we cancel? An examination of risk handling in travel social media before visiting ebola-free destinations. Journal of Hospitality and Tourism Management, 28, 5965. https://doi.org/10.1016/j.jhtm.2016.01.009

Mohseni, S., Jayashree, S., Rezaei, S., Kasim, A., \& Okumus, F. (2016). Attracting tourists to travel companies' websites: The structural relationship between website brand, personal value, shopping experience, perceived risk and purchase intention. Current Issues in Tourism, 21(6), 616-645. https://doi.org/10.1080/13683500.2016. 1200539

Money, R. B., \& Crotts, J. C. (2003). The effect of uncertainty avoidance on information search, planning, and purchases of international travel vacations. Tourism Management, 24(2), 191-202. https://doi.org/ 10.1016/s0261-5177(02)00057-2

Nazneen, S., Hong, X., \& Ud Din, N. (2020). COVID-19 crises and tourist travel risk perceptions. SSRN Electronic Journal. https:// doi.org/10.2139/ssrn.3592321

Neuburger, L., \& Egger, R. (2020). Travel risk perception and travel behavior during the COVID-19 pandemic 2020: A case study of the DACH region. Current Issues in Tourism, 24, 1-14. https:// doi.org/10.1080/13683500.2020.1803807

Nicola, M., Alsafi, Z., Sohrabi, C., Kerwan, A., Al-Jabir, A., Iosifidis, C., ... Agha, R. (2020). The socio-economic implications of the coronavirus pandemic (COVID-19): A review. International Journal of Surgery, 78, 185-193.

Novelli, M., Gussing Burgess, L., Jones, A., \& Ritchie, B. W. (2018). "no Ebola...still doomed" - The Ebola-induced tourism crisis. Annals of Tourism Research, 70, 76-87. https://doi.org/10.1016/j.annals. 2018.03.006

Pardo, R., \& Calvo, F. (2004). The cognitive dimension of public perceptions of science: Methodological issues. Public Understanding of Science, 13(3), 203-227. https://doi.org/10.1177/ 0963662504045002

Pennington-Gray, L., Schroeder, A., \& Kaplanidou, K. K. (2011). Examining the influence of past travel experience, general web searching behavior and risk perception on future travel intentions. International Journal of Safety and Security in Tourism, 1(1), 64 92.

Polas, M. R. H., Sahidullah, M., Hossain, M. I., Karim, A. M., Prabhakaran, S., \& Khan, A. M. (2019). Antecedent and consequences of risk perception on tourist decision making towards the sustainable medical tourism development in Bangladesh. Journal of Tourism Management Research, 6(1), 93-108. https://doi.org/10. 18488/journal.31.2019.61.93.108

Provost, S., \& Soto, J. C. (2002). Perception and knowledge about some infectious diseases among travelers from Québec, Canada. Journal of Travel Medicine, 9(4), 184-189. https://doi.org/10.2310/7060. 2002.24550

Qi, C. X., Gibson, H. J., \& Zhang, J. J. (2009). Perceptions of risk and travel intentions: The case of China and the Beijing Olympic games. Journal of Sport \& Tourism, 14(1), 43-67. https://doi.org/10.1080/ 14775080902847439

Quintal, V., \& Polczynski, A. (2010). Factors influencing tourists' revisit intentions. Asia Pacific Journal of Marketing and Logistics, 22(4), 554-578. https://doi.org/10.1108/13555851011090565v 
Quintal, V. A., Lee, J. A., \& Soutar, G. N. (2010). Risk, uncertainty and the theory of planned behavior: A tourism example. Tourism Management, 31(6), 797-805. https://doi.org/10.1016/j.tourman. 2009.08.006

Reisinger, Y., \& Mavondo, F. (2005). Travel anxiety and intentions to travel internationally: Implications of travel risk perception. Journal of Travel Research, 43(3), 212-225. https://doi.org/10.1177/ 0047287504272017

Reza, J. M., \& Samiei, N. (2012). Perceived risks in travelling to the Islamic Republic of Iran. Journal of Islamic Marketing, 3(2), 175189. https://doi.org/10.1108/17590831211232573

Rittichainuwat, B. N., \& Chakraborty, G. (2009). Perceived travel risks regarding terrorism and disease: The case of Thailand. Tourism Management, 30(3), 410-418. https://doi.org/10.1016/j.tourman. 2008.08.001

Rittichainuwat, B., Nelson, R., \& Rahmafitria, F. (2018). Applying the perceived probability of risk and bias toward optimism: Implications for travel decisions in the face of natural disasters. Tourism Management, 66, 221-232. https://doi.org/10.1016/j.tourman. 2017.09.013

Roehl, W., \& Fesenmaier, D. (1992). Risk perceptions and pleasure travel: An exploratory analysis. Journal of Travel Research, 30(4), 1726. https://doi.org/10.1177/004728759203000403

Rubin, G. J., Amlôt, R., Page, L., \& Wessely, S. (2009). Public perceptions, anxiety, and behavior change in relation to the swine flu outbreak: Cross sectional telephone survey. British Medical Journal, 339, b2651. https://doi.org/10.1136/bmj.b2651

Reichel, A., Fuchs, G., \& Uriely, N. (2007). Perceived Risk and the NonInstitutionalized Tourist Role: The Case of Israeli Student ExBackpackers. Journal of Travel Research, 46(2), 217-226. https:/ doi.org/10.1177/0047287507299580.

Senbeto, D. L., \& Hon, A. H. (2020). The impacts of social and economic crises on tourist behavior and expenditure: An evolutionary approach. Current Issues in Tourism, 23(6), 740-755. https://doi.org/ $10.1080 / 13683500.2018 .1546674$

Sönmez, S., \& Graefe, A. (1998a). Determining future travel behavior from past travel experience and perceptions of risk and safety. Journal of Travel Research, 37(2), 172-177. https://doi.org/10. $1177 / 004728759803700209$

Sönmez, S. F., \& Graefe, A. R. (1998b). Influence of terrorism risk on foreign tourism decisions. Annals of Tourism Research, 25(1), 112144. https://doi.org/10.1016/S0160-7383(97)00072-8

Tanovic, E., Gee, D. G., \& Joormann, J. (2018). Intolerance of uncertainty: Neural and psychophysiological correlates of the perception of uncertainty as threatening. Clinical Psychology Review, 60, 87-99. https://doi.org/10.1016/j.cpr.2018.01.001

Taymoori, P., Molina, Y., \& Roshani, D. (2014). Effects of a randomized controlled trial to increase repeat mammography screening in Iranian women. Cancer Nursing, 38(4), 288-296. https://doi.org/ $10.1097 /$ ncc. 0000000000000185

The World Bank. (2020). International tourism, expenditures (current US\$). Retrieved April 24, 2020, from https://data.worldbank.org/ indicator/ST.INT.XPND.CD?end $=2018 \&$ most_recent_value_ desc $=$ false \&start $=2018 \& v i e w=$ map \&year $=2017$.

Tomé, L. M. (2020). Setor de turismo: impactos da pandemia. Caderno Setorial ETENE, 124, agosto. Retrieved September 19, 2020, from https://www.bnb.gov.br/documents/80223/7600112/2020 CDS 122_turismo.pdf/748e1bcd-8bf3-18d5-aaf0-f1 1cda0e3052

Tsaur, S., Tzeng, G., \& Wang, K. (1997). Evaluating tourist risks from fuzzy perspectives. Annals of Tourism Research, 24(4), 796-812. https://doi.org/10.1016/s0160-7383(97)00059-5
Tversky, A., \& Kahneman, D. (1992). Advances in prospect theory: Cumulative representation of uncertainty. Journal of Risk and Uncertainty, 5, 297-323. https://doi.org/10.1007/BF00122574

Van der Pligt, J. (1996). Risk Perception and Self-Protective Behavior. European Psychologist, 1(1), 34 43. https://doi.org/10.1027/10169040.1.1.34.

Wen, J., Wang, W., Kozak, M., Liu, X., \& Hou, H. (2020). Many brains are better than one: The importance of interdisciplinary studies on COVID-19 in and beyond tourism. Tourism Recreation Research, 46, 1-4. https://doi.org/10.1080/02508281.2020.1761120

Whitehead, L. C. (2007). Methodological and ethical issues in internetmediated research in the field of health: An integrated review of the literature. Social Science \& Medicine, 65(4), 782-791. https://doi. org/10.1016/j.socscimed.2007.03.005

Williams, A. M., \& Baláž, V. (2013). Tourism, risk tolerance and competences: Travel organization and tourism hazards. Tourism Management, 35, 209-221. https://doi.org/10.1016/j.tourman. 2012.07.006

World Health Organization (WHO). (2020). Coronavirus disease 2019 (COVID-19). Situation Report - 76. Retrieved May 27, 2020, from https://www.who.int/docs/default-source/coronaviruse/situationreports/20200405-sitrep-76-covid-19.pdf?sfvrsn=6ecf0977_4.

World Tourism Organization (UNWTO). (1980). International Tourism in Figures 1950-1979 (English version). https://doi.org/10.18111/ 9789284409549

World Tourism Organization (UNWTO). (2019). International Tourism Highlights, 2019 Edition. https://doi.org/10.18111/9789284421152.

World Tourism Organization (UNWTO). (2020a). International tourist numbers could fall 60-80\% in 2020, UNWTO reports. https://www. unwto.org/news/covid-19-international-tourist-numbers-could-fall60-80-in-2020.

World Tourism Organization (UNWTO). (2020b). COVID-19 related travel restrictions. A global review for tourism. Third report as of 8 Retrieved May 28, 2020, from. https://webunwto.s3.eu-west-1. amazonaws.com/s3fs-public/2020-05/TravelRestrictions-08-Mayo. pdf

World Tourism Organization (UNWTO). (2020c). International tourist numbers down $65 \%$ in first half of 2020, UNWTO reports. Retrieved October 15, 2020, from https://www.unwto.org/news/internationaltourist-numbers-down-65-in-first-half-of-2020-unwto-reports.

Xie, C., Huang, Q., Lin, Z., \& Chen, Y. (2020). Destination risk perception, image and satisfaction: The moderating effects of public opinion climate of risk. Journal of Hospitality and Tourism Management, 44, 122-130. https://doi.org/10.1016/j.jhtm.2020.03. 007

Zhang, H., Li, L., Yang, Y., \& Zhang, J. (2018). Why do domestic tourists choose to consume local food? The differential and nonmonotonic moderating effects of subjective knowledge. Journal of Destination Marketing \& Management, 10, 68-77. https://doi.org/ 10.1016/j.jdmm.2018.06.001

Zhu, H., \& Deng, F. (2020). How to influence rural tourism intention by risk knowledge during COVID-19 containment in China: Mediating role of risk perception and attitude. International Journal of Environmental Research and Public Health, 17(10), 3514. https:// doi.org/10.3390/ijerph17103514

Publisher's Note Springer Nature remains neutral with regard to jurisdictional claims in published maps and institutional affiliations. 